\title{
Outcome Summary of the International Experience in Developing the Financial Resources of Universities
}

\author{
Abdulrahman Obaid Al-Youbi, Adnan Hamza Mohammad Zahed, \\ and Abdullah Atalar
}

It is widely believed that economic returns of tertiary education to the public are much higher than those in other sectors of the economy. Excellence in education and research, therefore, is an important factor for the welfare of countries. To improve the well-being of their citizens, governments invested heavily in higher education. The number of higher education institutes in the world has reached 18,000 , and as a result, a larger fraction of people is getting tertiary education degrees. The expansion of the university system required a corresponding increase in the funding. Growth in the number of higher education institutes in both developed and developing world increased the competition between those institutes. Almost everything a university does costs money, especially in a competitive environment. The expenditures of universities inflated above the inflation rate in the developed world. In the developing world, university budgets are under strain, because of the increasing number of students. Consequently, university administrators all over the world are in a constant search for more funds.

If higher education institutes are expected to deliver high-quality education and research, their sustainable funding is crucial for the future of that nation. Many governments recognize this fact and support the higher education institutes directly as much as possible within the limitations of their budgets. Research funding agencies present in most countries support the research in universities in a competitive manner. In recent years, they preferred to support ideas that may convert into innovative products.

\section{A. O. AI-Youbi \\ President of King Abdulaziz University, King Abdulaziz University, Jeddah, Saudi Arabia}

\footnotetext{
A. H. M. Zahed ( $\square)$

Abdulaziz University, Jeddah, Saudi Arabia

e-mail: iab@kau.edu.sa

A. Atalar

Bilkent University, Ankara, Turkey

e-mail: aatalar@bilkent.edu.tr
}

Secretary-General of the International Advisory Board, King
While governmental sources are a major part of the funding of most universities, economic downturns, as in the case of the COVID-19 crisis, may reduce government funding. The university administrators are looking for other sources to compete in a global setting.

While tuition income is also a major source for universities in some countries, it may be very small or nonexistent in the rest. For top universities of the developed world, tuition from international students attracted from the young population of developing countries and branch campuses established in those countries turned out to be another source of income.

As the government subsidy is shrinking, many universities in the developed nations try to stabilize their income by forming an endowment to help them in difficult times. For example, many private and public universities of the United States were able to build significant sized endowments using gifts from their alumni and by philanthropy from private sources. To diversify their revenue sources, universities became more commercial oriented organizations compared to what they were 50 years ago. They try to convert their research findings into income sources by getting patents of their ideas and licensing them to commercial entities to collect royalty income. University faculty members are also encouraged to get involved in startup companies to fuel the local economy and generate more jobs.

The chapters in this book gave the visions of some academic leaders in the search of more funding for their universities, especially in the aftermath of the COVID-19 crisis. Outcomes of all chapters, discussing different strategies and methods to secure funding for higher education institutes, are summarized below:

- University administrators will obtain a better ability to construct future-based funding that aims at growth and innovation across an institution during a time of constant change. This is done through an analysis of the existing funding and budgeting models open to institutions, the strengths and weaknesses of each model, and how to 
leverage an institution's key differentiators to develop external funding sources for diversification.

- University administrators understand that reliance on government funding, even for public universities, is becoming fragile and alternative sources are needed.

- International full-cost-plus-fee paying students have become a major source of income of universities.

- The resilience of universities against external events needs to be enhanced.

- The COVID-19 crisis in 2020 will put a strain on government budgets for the years to come. Because of the crisis, the number of international students and the corresponding tuition income is also likely to decrease.

- Assets of a higher education institute include everything that it owns, controls, and influences, including people. Historically, monetization meant converting an asset into cash or liquidating it. It is better understood as a two-part set of tactics, i.e., pulling resources from some assets and investing them in other assets.

- Higher education institutes may employ six monetization tactics:

- Wringing out resources to invest;

- Borrowing resources to invest;

- Trading resources to invest;

- Soliciting resources to invest;

- Selling monetized assets; and

- Creating new assets. These are typically carried out through advancement offices or strategic plan initiatives of universities.

Each tactic has special features and limitations, and its utility depends a lot on the assets being monetized. For example, parking structures and academic departments are very different assets, monetized differently.

- Current issues facing most higher education institutes require much swifter and more dramatic responses than in the past.

- The implied stability of annual budgets is being supplanted by the impatient pursuit of survival and growth.

- Worthy academic purposes through asset monetization are ultimately reflected financially in two metrics, net income in the near term and, over the longer term, growth in net assets.

- Comparing decades-long changes in net assets with rival peer universities is an unambiguous metric of the institution's success.

- There are marked international variations in funding models for public universities and also variations within countries. Learning from best practices and adapting those practices to the local context will be required.

- Alternative sources of income for a university include philanthropy, links with industry/business, commercialization of research, digital technologies, and future horizons.
- Tuition income, whether as fees from individual students, in fellowships or scholarships or as in block grants from governments or other funding agencies, remains the mainstay of university income.

- The presence or raise of tuition fees in public universities are in many countries the subject of intense political debate, centered on social mobility. Since high tuition fees may reduce social mobility, income-contingent loan schemes can be a way to offset the negative impact of a rise in tuition fees.

- The impacts of funding and budgeting in the era of the COVID-19 pandemic will alter an institution's focus and ability to fund operations and key objectives. This includes assessing internal funding models during COVID-19 and examining the likely external research funding landscape during and following the global pandemic.

- In a world of scarce resources where multiple non-profit organizations need public resources, philanthropy provides one additional way for universities to gain additional resources.

- Private philanthropy is important at any time, but even more so when a crisis arises such as a COVID-19 pandemic. Private philanthropy and an endowment is one such revenue stream.

- Educational philanthropy ensures a university's sustainability and fosters growth and discovery. It enables a university to help shape its community's social, economic, and technological development.

- An alternative model of endowment development may be applicable in developing nations. Since not all nations have a philanthropy culture or a donation motivating tax system, a university in such a country must find new ways of raising an endowment.

- Endowments and gifts are important for public universities, even if they are substantially smaller than for private universities. Endowments enable the university to generate revenue for important institutional activities such as establishing endowed chairs and centers, building research centers and the like, and creating additional investment opportunities.

- In many societies, citizens want to support universities beyond the taxes they pay to local governments in order to contribute to higher education. There are four reasons donors give to a university: (a) to repay the institution for what they learned, (b) to make an impact, (c) to create a legacy, and (d) to gain a tax benefit.

- Some Governments support universities by matching the donations they receive to nurture a philosophy of giving in their communities.

- Fundraising methodology involves branding, community outreach, networking, and strategic messaging which also makes fundraising entrepreneurial. 
- The more universities engage with communities to share their mission, goals, and values, the more they can garner support from alumni and benefactors.

- The primary leader of fund-raising is the university president or chancellor. The Board of Trustees also plays a significant role.

- A fully-staffed development office is essential for a successful capital campaign. Benefactions celebrate not just the mission of a university, but also friendship, bonding, and trust between a benefactor and the institution or its leaders.

- Donors differ across generations. This requires periodic re-defining of philanthropic engagement and challenges the university to renew and review its strategies.

- A university with a campus is basically a small city, where full control is in the hands of the university administration. Many such universities rent spaces or outsource to third parties to cover the basic needs of the campus population. Income from rental can be considered a low-risk income. Some of these services can be turned into seeds of new companies, which can grow beyond the limits of the campus.

- The basic needs of this small town, like bookstore, food service, market, shopping center, energy production, hotel, facility management, security can be the breeding ground for those new companies, which are totally owned by the university.

- The companies should be run by professionals, not by the university administrators, who are not trained to be efficient business executives. If those companies become successful outside the campus limits, the university may benefit from the profits of such companies, as an alternative form of an endowment.

- Technology transfer represents an opportunity for universities to secure a return on their academic investment which can then be cycled back into the institution for its further growth and development. Technology transfer can occur in virtually every field of study or discipline, with the goal of bringing discoveries to the market, either individually or collectively.

- During the past 20 years we have seen the evolution of an "Entrepreneurial Ecosystem" for technology transfer structured around three fundamental engines: (1) discovery, (2) enablement, and (3) economic development.

- Universities may increase their funding through knowledge transfer: research contracts with outside partners, start-ups by students or staff from the university or patents.

- While recognizing that local or national cultures vary and play an important role in tech transfer, creating a campus culture that values, supports, and promotes tech transfer is essential, requiring university-wide commitment, visible leadership, faculty and student engagement, the highest quality of research, and incentivization of both creativity and entrepreneurship.

- To promote technology transfer effectively university leaders need to: (a) provide a clear vision for the initiative, (b) break down silos, (c) remove barriers, (d) provide resources, (e) hire the right leaders, (f) set appropriate expectations, and $(\mathrm{g})$ ensure fair and faculty-favorable incentives.

- It is always possible to extract new income resources based on the participation of all those who benefit from higher education, including public and private sector companies, institutions, and organizations, as well as the local community.

- As an example of funding development, the leading university, King Abdulaziz University, of a developing nation, Saudi Arabia, has managed to develop additional financial resources on top of the funds allocated by the government. The university generates its funding from the following methods:

- Establishing an investment company for the university, and providing consultations and research to the public and private sectors;

- Marketing research products and inventions by transferring technology,

- Encouraging creativity and entrepreneurship;

- Making research centers available to solve community problems,

- Developing a research endowment,

- Providing its services to the community through diplomas in the specializations required in the labor market, and using e-learning methods to provide paid education and training globally;

- Providing online consultations and studies in many fields to the global community,

- Activating partnerships and opening investment prospects with big companies;

- Self-operating some university sectors in a commercial investment manner;

- Establishing a center for advanced health care and health tourism;

- Privatizing some service and research sectors and making them available for investment for everyone;

- Marketing the expertise and capabilities of the university, its laboratories, and research centers;

- Investing the university property (theatres, sports buildings, lands, etc.);

- Establishing companies for industries concerned with technology transfer and localization;

- Supporting innovation and encouraging patenting, then converting patents into a product. 


\begin{abstract}
Abdulrahman Obaid Al-Youbi is the President of King Abdulaziz University (KAU) and the President of the International Advisory Board (IAB) of KAU since 2016. He is a Professor of Chemistry at KAU since 2000. He earned a Ph.D. in Physical Chemistry from Essex University, UK in 1986. Throughout his career, Prof. Al-Youbi is an active researcher in his specialization, a passionate teacher, an academic and administrator. He participated in many research projects and published more than 150 papers in ranked scientific journals. He also supervised many graduate students. He has held a variety of Academic Administrative positions at KAU such as: In (2015-2016), he was Acting President of both KAU and Jeddah University, Vice President for Academic Affairs (2009-2016), Vice President (2002-2009), Dean of the Faculty of Science (1999-2002), Vice-Dean of the Faculty of Science (1992-1999), and Chairman of the Chemistry Department. As President of KAU, Prof. Al-Youbi has devoted his position to strengthen excellence in academics and research with a dedication to develop an innovative culture. Through President Al-Youbi's leadership, KAU has remained the top university, not only in Kingdom of Saudi Arabia, but also in the Arab World. His current focus is on expanding KAU's leadership by continuing to build on its long-standing strengths in education, research, entrepreneurship and Community Service to the people of Kingdom of Saudi Arabia. President Al-Youbi participated in more than eighty committees, boards, teams and working groups at KAU as well as at Saudi Ministry of Education level. In particular, he has participated in the committees that have established new universities in the Kingdom, (Taiba University, Jazan University, Tabuk University, and the Northern Border University). He has also attended many scientific conferences in the Kingdom and abroad. In addition to his membership in the first formation of the University Affairs Council in the Kingdom of Saudi Arabia.
\end{abstract}

Adnan Hamza Mohammad Zahed is Consultant to the President of King Abdulaziz University (KAU) since 2016 and the Secretary-General of the International Advisory Board (IAB) of KAU since 2010. He was the KAU Vice President for Graduate Studies and Scientific Research (2009-2016), and worked before that as Dean of Graduate Studies (2007-2009), and before that, he was Vice Dean of the Faculty of Engineering (1997-2007). Prof. Zahed is a full professor in the Chemical Engineering Department at KAU since 1996. He also worked in the industry sector as General Supervisor (Consultant) in Saudi Badrah Company (Jeddah, KSA, 19951996), Deputy General Manager at Savola Food Company in Jeddah
(1993-1995), and Deputy CEO of Tasali Company (Jeddah). He holds a B. Sc. in Chemical Engineering from King Fahd University of Petroleum and Minerals, KSA (1976), and a M.S (1979) and Ph.D. in Chemical Engineering from University of California (Davis), USA (1982). He published eleven books most of them in higher education, and more than 60 papers in international conferences and refereed journals, in addition to one patent and more than 75 technical reports written for many bodies of Saudi community. He also participated as a co-author of several University Guides such as the Graduate Studies Guide, Applicable Theses Guide, Thesis Writing Guide, Graduate Studies Procedure Guide, Faculty of Engineering Prospectus and Annual Report of Research Activities in Faculty of Engineering. Prof. Zahed was included in Marquis (Who's Who in the World 2006). He participated in four academic accreditation meetings in USA, and in more than 25 local and international conferences, symposia and forums. Prof. Zahed visited a number of distinguished American, European and Asian universities as a delegate of the Saudi Ministry of Education.

Prof. Abdullah Atalar received his B.S. degree from Middle East Technical University, Ankara, Turkey, in 1974 and his M.S. and Ph.D. degrees from Stanford University, Stanford, CA, in 1976 and 1978, respectively, all in Electrical Engineering. From 1978 to 1980, he was first a Postdoctoral Fellow and later an Engineering Research Associate at Stanford University. For about one year, he worked in Hewlett Packard Labs, Palo Alto. From 1980 to 1986, he was on the faculty of the Middle East Technical University as an Assistant Professor. In 1983, on leave from the University, he worked for Ernst Leitz Wetzlar (now Leica) in Wetzlar, Germany. In 1986, he joined the Bilkent University as the chairman of the Electrical and Electronics Engineering Department and served in the founding of the Department where he is currently a Professor. In 1995, he was a Visiting Professor at Stanford University. From 1996 to 2010, he was the Provost of Bilkent University. He is presently the Rector of the same university. Between 2004 and 2011, he served as a member of the Science Board of TUBITAK. His current research interests include microwave electronics and micromachined sensors. He was awarded the Science Award of the Turkish Scientific Research Council (TUBITAK) in 1994. He has been a member of the Turkish Academy of Sciences since 1997 and a Fellow of IEEE since 2007. Professor Atalar is a member of the KAU IAB.
Open Access This chapter is licensed under the terms of the Creative Commons Attribution 4.0 International License (http:// creativecommons.org/licenses/by/4.0/), which permits use, sharing, adaptation, distribution and reproduction in any medium or format, as long as you give appropriate credit to the original author(s) and the source, provide a link to the Creative Commons license and indicate if changes were made.
The images or other third party material in this chapter are included in the chapter's Creative Commons license, unless indicated otherwise in a credit line to the material. If material is not included in the chapter's Creative Commons license and your intended use is not permitted by statutory regulation or exceeds the permitted use, you will need to obtain permission directly from the copyright holder. 